\title{
Features of modern methods of teaching foreign languages
}

\author{
Abdurakhmanova Dilrabo Kadirjanovna ${ }^{1}$, Sadriddinova Dildora Maxammadjonovna ${ }^{2}$, \\ Abduvoxidova Xushnoza Muxtorali daughter ${ }^{3}$ \\ ${ }^{1,2}$ Senior Lecturer, Namangan State University, Uzbekistan \\ ${ }^{3}$ Master's degree in Foreign Philology, National University of Uzbekistan, Uzbekistan
}

Email:askarxadjayeva_a@umail.uz

\begin{abstract}
This article discusses the peculiarities of modern methods of teaching foreign languages. The advantages, advantages and disadvantages of using modern techniques are considered. The article proposes effective language teaching techniques.
\end{abstract}

Keywords: methodology, methodology, language, foreign language, modern methods, education, innovative technologies.

\section{INTRODUCTION}

In the methods of teaching the English language, the most applied were communicative-oriented concepts. Among them the most popular are communicative, project, intensive and activity-based methods.

A few words about the history of their appearance, development and basic provisions.

The nomination of a foreign culture as a learning goal raised the issue of the need to create a new methodological system that could achieve this goal in the most effective and rational way. Then the staff of the Department of Foreign Languages Training of the Lipetsk State Pedagogical Institute for a number of years developed the principles of communicative methodology.

The logic of the development of a communicative methodology led to the final nomination of a foreign culture as the goal of teaching foreign languages in school. A similar system can be built only on a communicative basis.

In addition, as the practice of using the communicative method has shown, it provides not only the assimilation of a foreign language as a means of communication, but also the development of the comprehensive qualities of the personality of the students.

Communicative method was the basis for creating textbooks on English in secondary school. The next method is the design method.

\section{MAIN PART}

Teaching foreign languages, being an integral part of the general education system, is subject to the main development trends of this system. This is most evident in the methods of instruction.

In the last two decades, a tendency has been formed in education, such as projectivity. This concept was formulated in the context of the program for the restructuring of education, proposed in the late 1970s by the Royal College of Arts in Great Britain. It is closely connected with the project culture, which arose as a result of the unification of the humanitarian, artistic and scientific and technical areas in education.

The project culture is, as it were, the general formula in which the art of planning, invention, creation, execution and design is realized and which is defined as design.

Mastering the culture of design, a schoolboy learns to think creatively, independently planning his actions, predicting possible options, solving the problems facing him, realizing the means and methods he has mastered. The design culture is now included in many areas of educational practice in the 
form of design methods and design teaching methods. The project method is actively included in the teaching of foreign languages.

A striking example of the application of the project method is the textbook "Project English", published in 1985 by the Oxford University Press. The author of the course is T. Hutchinson, a specialist in the field of communicative grammar teaching.

In modern conditions of rapid development of science and technology, the problem of transition to an intensive path of development is and is being solved in all spheres of society and at all stages of the formation of the individual and specialists. It is also relevant for teaching foreign languages. The search for the best ways to solve this problem, prompted the emergence of a method in the late sixties and early seventies of this century, which is based on a suggestive effect on students.

\section{RESEARCH ANALYSES}

Suggest a directional trend appeared in connection with the attempt of the Bulgarian physicianpsychotherapist Georgy Lozanov to use suggestion as a means of activating reserve mental abilities in the educational process, in particular, when teaching foreign languages.

Lozanov's ideas were the starting point for the construction of a number of methodical systems of intensive instruction in foreign languages. Initially, the intensive language teaching model for foreign languages was developed for the application of an adult contingent of trainees in short-term courses, but in the future the experience of successful implementation of an intensive training method and in other conditions was positive.

At present, intensive instruction in foreign languages is realized in various developing, newly created and operating methodological systems. This is due to the diversity of the specific objectives of teaching a foreign language to a different contingent of trainees, as well as the variety of learning conditions (a grid of study hours, their number, and the content of the training group).

Followers G. Lozanov in our country, developing his ideas, were GA Kitaigorodskaya, N.V. Smirnova, I.Yu. Shekter and others.

The most famous method is now the activation of the reserve capabilities of the individual and the collective GA Kitaigorodskaya. In the method of activation, the concept of intensive teaching of a foreign language is most vividly and fully reflected.

Separately and in more detail it is necessary to say about the distance form of training, which is the youngest of all named.

Distance learning is distance learning, that is, the learner is separated from the learner by distance. In our country this form of training was known as correspondence. In the practice of teaching foreign languages, it was not applied as widely as in other areas. There were extramural foreign language courses, and there were educational TV and radio programs for those who wanted to learn a foreign language. Language faculties and universities were limited to evening departments, since it is almost hopeless to teach practical knowledge of a foreign language in case of occasional meetings with a teacher.

In recent years, universities in various countries have drawn attention to the fact that it is possible to use computer-based telecommunications technologies for distance learning, including foreign languages.

\section{CONCLUSION}

In contrast to other forms of distance learning, training based on computer telecommunications provides opportunities:

$>$ prompt transmission of any information at a distance;

$>$ storing this information in memory for the required time, editing it, etc.

$>$ interactivity with the help of a specially created for these purposes

$>$ multimedia information and on-line feedback from the instructor and other participants in the training course;

$>$ access to various sources of information, including remote and distributed databases, numerous conferences around the world via the Internet.

$>$ organization of joint telecommunication projects, as well as international, electronic conferences, computer audio and video conferences. 


\section{REFERENCES}

1. Chicherova L.G. Engelsky in the sphere of consumer services: A manual on self-education --M.; Higher School, 1993-144p.

2. Shcherbakova N.I. Zvenigorodskaya N. English for professionals in the field of public catering = English for Cooking and Catering: Proc. Allowance for stud. Medium. Prof. Educational Institutions-M .: The Publishing Center "Akademiya" 2005-320 p

3. G. Lozanov "Suggestology" - Sofia: Science and Art. - 1971

4. Kitaigorodskaya GA The method of intensive instruction in foreign languages. M $\therefore$ High School., 2010

5. DiltsR. "NLP: effective leadership skills" - St. Petersburg. - 2009

6. Asher J.Language by command. The Total Physical Response to learning language // The wayof learning. Summer -1984

7. Adler G. "NLP modern psychotechnology." SPb - 20116. The main directions in the teaching of foreign languages in the XIX-XX / ed.I.V. Rakhmaninov-M .: "Pedagogy" - 2013 